\title{
In-hospital mortality of acute coronary syndrome in elderly patients
}

Omima E. Ahmed, MD, Samah I. Abohamr, MD, NBE, Shaima A. Alharbi, MSc, Dawood A. Aldrewesh, MSc, Abdulaziz S. Allihimy, MSc, Sarah A. Alkuraydis, MSc, Ibtihal M. Alhammad, MSc, Eman Elsheikh, FRCP, SCCT, Abmad S. Azazy, MD, Asim A. Mohammed, MD, Mehboob A. Dar, MD, Rami M. Abazid, FRCP, SCCT.

\begin{abstract}
الأهداف : تحليل تنبؤات الوفاة لدى المرضى المسنين الذين تم تشخيصهم بمتلازمة

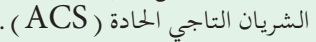

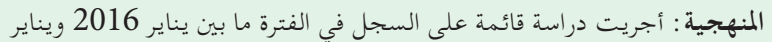

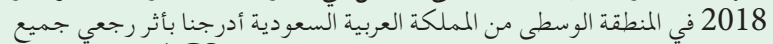

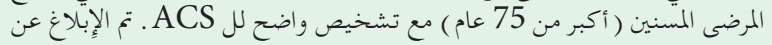

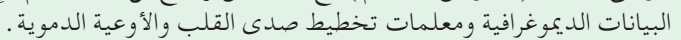

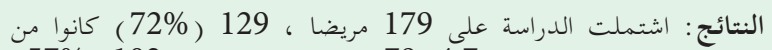

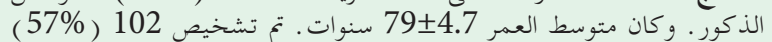

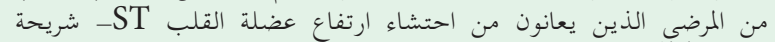

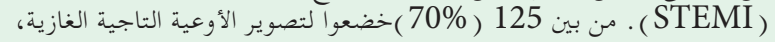

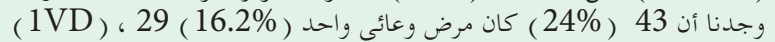

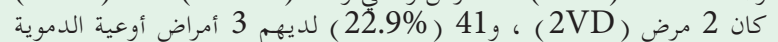
(3VD)

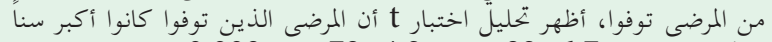

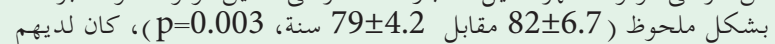

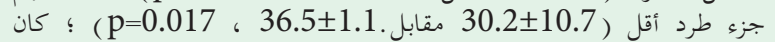
معدمل انتشاره STEMI أعلى في مجموعة الوفاة

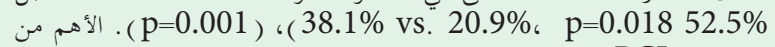

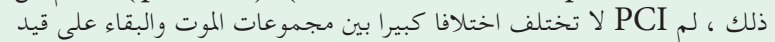

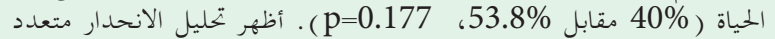
المتغيرات أن تنبؤات الوفاة كانت

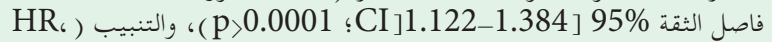

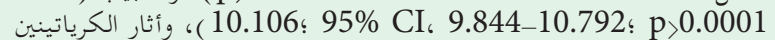
؛(CK-MB) (HR، 1.005؛ 95\% CI، 1.002-1.013؛ p=0.04) تنبأ في وفاة المستشفى

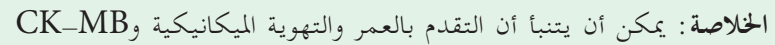

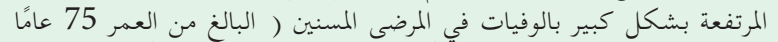

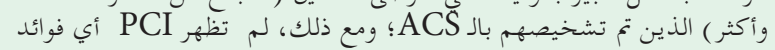
لتحسين الوفيات.
\end{abstract}

Objectives: To analyze predictors of death in elderly patients diagnosed with acute coronary syndrome (ACS).

Methods: A record-based study carried out between January 2016 and January 2018 at The central province in Saudi Arabia. All elderly patients ( $>75$ years) with definite diagnosis of ACS were retrospectively included. Demographic data, echocardiographic, and angiographic parameters were reported.

Results: A total of 179 patients were enrolled, 129 $(72 \%)$ were male. The mean age was $79 \pm 4.7$ years.
Approximately 102 (57\%) patients were diagnosed with ST-segment elevation myocardial infarction (STEMI). Of all 125 (70\%) underwent invasive coronary angiography, we found that $43(24 \%)$ had significant single vessel disease (1VD), 29 (16.2\%) had 2 vessel disease (2VD), and $41(22.9 \%)$ had 3 vessel disease (3VD) or left main stenosis. During hospitalization $21(11.7 \%)$ patients died, t-test analysis showed patients who died were significantly older $(82 \pm 6.7$ versus [vs.] $79 \pm 4.2$ years, $p=0.003)$. In addition we found that ejection fraction was lower in death group $(30.2 \% \pm 10.7)$ vs. $(36.5 \% \pm 1.1)$ in survivors, $p=0.017)$; STEMI was more common in death group $(90.5 \%)$ vs. $(52.5 \%)$ in survivors, $p=0.001)$; similarly, the prevalence of $3 \mathrm{VD}$ was higher in death group $(38.1 \%)$ vs. $(20.9 \%)$ in survivors, $p=0.018)$.Importantly, PCI was not significantly different between death and survival groups ( $40 \%$ vs. $53.8 \%, p=0.177$ ). A multivariate regression analysis demonstrated that predictors of death were: age (hazard ratio [HR], 1.214; 95\% confidence interval [CI], 1.122-1.384; $p<0.0001$ ), intubation (HR, 10.106; 95\% CI, 9.844-10.792; $p<0.0001)$, and raised creatinine kinase-MB (CK-MB) (HR, 1.005; 95\% CI, $1.002-1.013 ; p=0.04)$ predicted in hospital death.

Conclusion: Older age, mechanical ventilation and raised CK-MB can significantly predict death in elderly patients (>75-year-old) diagnosed with ACS; nevertheless, PCI showed no survival benefits.

\section{Saudi Med J 2019; Vol. 40 (10): 1003-1007} doi: 10.15537/smj.2019.10.24583

From the Department of Cardiology (Ahmed, Mohammed, Dar Abazid), Prince Sultan Cardiac Center Qassim; from the College of Medicine (Alharbi, Aldrewesh, Allihimy, Alkuraydis, Alhammad), Al Qassim University, Buraidah; from the Department of Cardiology (Abohamr, Azazy), King Saud Medical City, Riyadh; from the Department of Cardiology (Abohamr, Elsheikh), Tanta University Hospital, Cairo, Egypt; from the Department of Cardiology (Elsheikh), King Faisal University, Al Hasa, Kingdom of Saudi Arabia; and from the Department of Nuclear Medicine (Abazid), London Health Science Center, Ontario, Canada.

Received 5th August 2019. Accepted 17th September 2019.

Address correspondence and reprint request to: Dr. Omima E. Ahmed, Department of Cardiology, Prince Sultan Cardiac Center Qassim, Buraidah, Kingdom of Saudi Arabia. E-mail:dr.omima@hotmail.com ORCID ID: https://orcid.org/0000-0002-2910-5178 
$\mathrm{C}$ oronary artery disease (CAD) is considered as one of the most common health issues in different age groups. In addition, it has been more frequently encountered in older individuals, due to increased life expectancy and the adoption of sedentary lifestyles. ${ }^{1,2}$ Over the past years, World Health Organization reported that the mortality of CAD in Saudi Arabia is approximately $24 \%$ of total deaths and ranked Saudi Arabia as the 34th in the world. ${ }^{1}$ Acute coronary syndrome (ACS) is a common clinical presentation of $\mathrm{CAD}$ which is associated with significant hospitalizations and emergency visits worldwide each year. ${ }^{3}$

Multiple studies reported that older age as a significant predictor of in-hospital death and poor clinical outcomes in patients diagnosed with ACS, due to the higher prevalence of CAD risk factors and its related complications. ${ }^{4-7}$ Although patients older than 65 years encountered approximately $60 \%$ of hospitalization for ACS, the exact incidence rate of ACS in patients older than 75-year is not well- known. Importantly, guidelines directed therapy for ACS is suboptimal in elderly patients; nevertheless, they have more risk of medical and procedures complications. ${ }^{5}$ elderly patients $(>75$ years) with ACS were under-represented and account less than $10 \%$ of all subjects included in clinical trials. ${ }^{8}$ Of note, in Saudi Arabia there is no study investigated in-hospital mortality of ACS in patients older than 75 years; thus, the aim of this study is to analyze mortality and the outcome of invasive procedures compared to medical treatment in this age group.

Methods. A record-based historical prospective study between January 2016 and January 2018 The central province in Saudi Arabia. All elderly individuals aged more than 75 years old with a definitive diagnosis of ACS including unstable angina, non ST-segment elevation myocardial infarction (NSTEMI), and ST-segment elevation myocardial infarction (STEMI) in a tertiary care cardiac center in the central region of Saudi Arabia were selected. We reported the demographic data of the patients such as age, gender, risk factors, symptoms at time of presentation, electrocardiogram findings, laboratory investigations, coronary angiographic data, percutaneous coronary interventions (PCI) data, echocardiographic parameters, hospital stay, and final diagnosis and in hospital mortality. The institutional

Disclosure. Authors have no conflict of interests, and the work was not supported or funded by any drug company. and regional ethical committee approved the study protocol.

Statistical analysis. A 2-sample t-test was used for normally distributed continuous variables between patients who died and survived patients. To compare the outcome between interventional versus (vs.) noninterventional groups, Chi-square test was run for categorical variables, and Mann-Whitney test was used to compare length of stay between the groups. A $p$ value $<0.05$ was considered statistically significant. All statistical analyses were performed by IBM SPSS for Windows, version 19.0 (SPSS Inc., Chicago, IL, USA).

Results. A total of 179 patients were included in the study with mean age $79 \pm 4.7$ years, $129(72 \%)$ were male. They presented with ACS either STEMI (57\%) or NSTEMI (77\%). Approximately $62 \%$ of the patients were diabetic, 63 were hypertensive, nearly 13\% were dyslipidemic, $6 \%$ were smoker, and $1 \%$ family history of CAD. There was no significant gender differences regarding diabetes $(76[60 \%)]$ for men vs. $35[70 \%]$ for women, $p=0.7]$ and in hypertension (73 [57\%] for men vs. $41[82 \%]$ for women, $p=0.1]$.

As regard to coronary angiography, 43 patients (24\%) had single vessel disease (1VD), 29 patients $(16.2 \%)$ had $2 \mathrm{VD}$ and 41 patients $(22 \%)$ had left main or $3 \mathrm{VD}$. Of those presented with STEMI, 93 patients had PCI for culprit lesion. Other clinical characteristics shown in Table 1.

In-hospital death. During hospitalization 21 (11.7\%) died. The t-test analysis showed that patients who died were significantly older $(82 \pm 6.7$ vs. $79 \pm 4.2, p=0.003)$, higher prevalence of STEMI $(90.5 \%$ vs. $52.5 \%$, $p=0.001)$, lower Ejection fraction (EF) $(30.2 \pm 10.7$ vs. $36.5 \pm 1.1, p=0.017)$, more of those with $3 \mathrm{VD}(38.1 \%$ vs. $20.9 \%, p=0.018)$. Importantly, PCI was performed in $(40.0 \%)$ of death group and $(53.8 \%)$ of survivors which was statistically non-significant $(\mathrm{p}=0.177)$. Other difference between groups seen in Table 1 .

We ran a univariate regression including all variables that significantly associated with death and we found that age, creatinine kinase-MB (CKMB), creatinine and mechanical ventilation was significant predictors of death (Table 2). However, multivariate regression showed age, CKMB and mechanical ventilation were significantly predictors of in-hospital death Table 2 .

Discussion. With the spread and improvement of medical services, the number of elderly individuals in the community has significantly increased. ${ }^{9}$ At the same time, percentage of elderly patients presented with ACS is increasingly year-by-year. ${ }^{10}$ In contrast to younger 
Table 1 - The baseline characteristic of elderly patients.

\begin{tabular}{|c|c|c|c|c|}
\hline Variables & All patients & Death & No death & $P$-value \\
\hline Number of patients & $179(100)$ & $21(11.7)$ & $158(88.3)$ & - \\
\hline Gender - men & $129(72.1)$ & $14 \quad(66.7)$ & $115(72.8)$ & 0.362 \\
\hline Age (years), mean $\pm S D$ & $79 \pm 4.7$ & $82 \pm 6.7$ & $79 \pm 4.2$ & 0.003 \\
\hline Diabetes mellitus, & $111(62.0)$ & $9 \quad(42.9)$ & $102(64.6)$ & 0.048 \\
\hline Hypertension, & $114(63.7)$ & $14 \quad(66.7)$ & $100(63.3)$ & 0.483 \\
\hline Dyslipidemia, & $23(12.8)$ & 0 & $23(14.6)$ & 0.046 \\
\hline Family history of coronary artery disease, & $1(0.6)$ & 0 & $1 \quad(0.6)$ & 0.883 \\
\hline Current smoking, & $11(6.1)$ & $1 \quad(4.8)$ & $10 \quad(6.3)$ & 0.622 \\
\hline ST-segment elevation myocardial infarction & $102(57.0)$ & $19(90.5)$ & $83(52.5)$ & \\
\hline $\begin{array}{l}\text { Non ST-segment elevation myocardial } \\
\text { infarction }\end{array}$ & $77(43.0)$ & $2 \quad(9.5)$ & $75(47.5)$ & 0.001 \\
\hline Percutaneous coronary interventions & $93(52.2)$ & $8 \quad(40.0)$ & $85(53.8)$ & 0.177 \\
\hline Ejection fraction mean \pm SD & $35.8 \pm 11.2$ & $30.2 \pm 10.7$ & $36.5 \pm 1.1$ & 0.017 \\
\hline $1 \mathrm{VD}$ & $43(24.0)$ & $1 \quad(4.8)$ & $42(26.6)$ & \\
\hline $2 \mathrm{VD}$ & $29(16.2)$ & $3(14.3)$ & $26(16.5)$ & 0.018 \\
\hline $\mathrm{LM} / 3 \mathrm{VD}$ & $41(22.9)$ & $8 \quad(38.1)$ & $33(20.9)$ & \\
\hline Significant valvular disease & $59(34.1)$ & $12(63.2)$ & $47(30.5)$ & 0.006 \\
\hline Creatinine kinase- $\mathrm{MB}$, mean $\pm \mathrm{SD}$ & $79 \pm 123$ & $186 \pm 242$ & $67 \pm 97$ & 0.001 \\
\hline Intubation & $16(8.9)$ & $13(61.9)$ & $3 \quad(1.9)$ & 0.001 \\
\hline Cardio shock & $26(14.5)$ & $20(95.2)$ & $6 \quad(3.8)$ & 0.001 \\
\hline Complete heart block & $5(2.8)$ & $3(15.0)$ & $2 \quad(1.3)$ & 0.011 \\
\hline White blood cell, mean \pm SD & $17 \pm 9$ & $14 \pm 5$ & $18.1 \pm 10$ & 0.870 \\
\hline Hemoglobin, mean \pm SD & $12.4 \pm 2$ & $12.5 \pm 3$ & $12 \pm 2$ & 0.846 \\
\hline Creatinine, mean $\pm S D$ & $108 \pm 56$ & $156 \pm 74$ & $102 \pm 51$ & 0.001 \\
\hline Length of stay, mean \pm SD & $5.3 \pm 5$ & $4.2 \pm 6$ & $5.4 \pm 5$ & 0.075 \\
\hline
\end{tabular}

Table 1 - Univariante binary regression of variables associated with higher mortality and multivariate binary regression including variables with $p$ value $<0.1$.

\begin{tabular}{|c|c|c|c|c|c|c|c|c|}
\hline \multirow{3}{*}{ Variable } & \multicolumn{4}{|c|}{$\begin{array}{l}\text { Univariate binary regression } \\
\text { for death }\end{array}$} & \multicolumn{4}{|c|}{$\begin{array}{c}\text { Multivariate binary regression } \\
\text { for death }\end{array}$} \\
\hline & \multicolumn{3}{|c|}{$95 \% \mathrm{CI}$ for $\operatorname{EXP}(\mathrm{B})$} & \multirow{2}{*}{$P$-value } & \multicolumn{3}{|c|}{$95 \% \mathrm{CI}$ for $\operatorname{EXP}(\mathrm{B})$} & \multirow{2}{*}{$P$-value } \\
\hline & $\operatorname{EXP}(B)$ & Lower & Upper & & $\operatorname{EXP}(B)$ & Lower & Upper & \\
\hline Age (years) & 1.258 & 1.055 & 1.500 & 0.010 & 1.214 & 1.122 & 1.384 & 0.000 \\
\hline Diabetes mellitus & 4.394 & 0.275 & 70.277 & 0.295 & - & - & - & - \\
\hline STEMI & 1.374 & 0.129 & 14.658 & 0.793 & - & - & - & - \\
\hline Ejection fraction & 0.970 & 0.844 & 1.115 & 0.670 & - & - & - & - \\
\hline Sig-VHD & 0.182 & 0.022 & 1.468 & 0.110 & - & - & - & - \\
\hline Creatinine kinase-MB & 1.007 & 1.000 & 1.014 & 0.036 & 1.005 & 1.002 & 1.013 & 0.04 \\
\hline Intubation & 10.005 & 9.023 & 10.109 & 0.001 & 10.106 & 9.844 & 10.792 & 0.000 \\
\hline Complete heart block & 0.090 & 0.001 & 9.491 & 0.311 & - & - & - & - \\
\hline $\mathrm{CR}$ & 1.031 & 1.002 & 1.060 & 0.034 & 0.988 & 0.968 & 1.009 & 0.262 \\
\hline
\end{tabular}

patients, elderly usually present with atypical symptoms, have more endothelial dysfunction, extensive CAD, and more non-cardiac morbidities. ${ }^{11}$

According to our knowledge, the data about in-hospital mortality of elderly presented with ACS in Saudi Arabia is insufficient. The current study demonstrated that elderly patients presented with ACS had approximately $12 \%$ of in-hospital death. In addition, we found that the most meaning predictors of in-hospital mortality were advanced age and elevated cardiac enzymes at the time of presentation. On the other hand, PCI had no effect on the mortality rate. ${ }^{12}$ These results are similar to a previous study of Bauer et $\mathrm{al}^{11}$ who investigated risk of mortality in elderly undergone PCI and stated that age is a strong predictor of in hospital death. In addition, they found that patients 
$\geq 75$ year-old has a 3-fold mortality when compared to a younger age group. Moreover, our results were similar to that of Rahman et al, ${ }^{13}$ who found that the higher levels of CKMB and other cardiac biomarkers were associated with a worse outcome and an increase in mortality rate.

In the present study, we found that hemodynamic instability and respiratory failure that required mechanical ventilation were important predictors of in-hospital death that was reported by previous studies. ${ }^{11}$ Hemodynamic instability and respiratory failure may occur at time of presentation or during hospitalization due to either pump failure, mechanical complications or a consequence of concomitant respiratory diseases. ${ }^{14}$

Moreover we found that early revascularization with PCI had no significant impact on mortality. Our results were differ from the Global Use of Strategies to Open Occluded Coronary Arteries in Acute Coronary Syndrome (GUSTO IIb) trial that showed PCI leads to significant reduction in death among patients more 70 years old. This difference can be explained by the older age of the included patients in our study and the new advancement of adherent medical treatment. ${ }^{15}$ Although there are no age limits for coronary arteries revascularization, PCI still considered a challenge in elderly individuals due to the extensive and complexity of coronary lesions, higher contrast induced nephropathy, vascular, and bleeding complications. ${ }^{16-18}$

In the same context, Bruer et $\mathrm{a}^{11}$ reported that patients older than 75 years undergoing PCI for ACS or stable angina had high rate of procedure related complications.

Study limitations. It is a single center study, based on a retrospective review of patients' data. Our results concern with in-hospital death predictors in elderly patients managed in a tertiary care center; thus, our findings can not be generalized on primary non-PCI capable hospitals. Lastly, relatively low number population involved can limit the conclusiveness of our results.

In conclusion, the mortality rate is approximately $12 \%$ in patients older than 75 years. Age, high cardiac enzymes at time of presentation, and need to mechanical ventilation support are significant predictors for in hospital mortality. Importantly, no survival benefits was shown with primary or early PCI in elderly presented with ACS. The decision of performing PCI should take in consideration age of the patient as well as associated comorbid diseases and hemodynamic state.

Further randomized prospective studies are required to assess revascularizations versus optimal medical management of ACS in this group of patients.

\section{References}

1. Wiviott SD, Braunwald E, McCabe CH, Montalescot G, Ruzyllo W, Gottlieb S, et al. Prasugrel versus clopidogrel in patients with acute coronary syndromes. N Engl J Med 2007; 357: 2001-2015.

2. Knuuti J, Wijns W, Saraste A, Capodanno D, Barbato E, FunckBrentano C, et al. 2019 ESC Guidelines for the diagnosis and management of chronic coronary syndromes. Eur Heart J 2019; pii: ehz425.

3. Fox KA, Carruthers KF, Dunbar DR, Graham C, Manning JR, De Raedt H, et al. Underestimated and under-recognized: the late consequences of acute coronary syndrome (GRACE UK-Belgian Study). Eur Heart J 2010; 31: 2755-2764.

4. Dai X, Busby-Whitehead J, Alexander KP. Acute coronary syndrome in the older adults. J Geriatr Cardiol 2016; 13: 101-108.

5. Amsterdam EA, Wenger NK, Brindis RG, et al. 2014 AHA/ ACC Guideline for the management of patients with non-STelevation acute coronary syndromes: a report of the American College of Cardiology/American Heart Association Task Force on Practice Guidelines. J Am Coll Cardiol 2014; 64: e139-e228.

6. Levine GN, Bates ER, Blankenship JC, Bailey SR, Bittl JA, Cercek B, et al. 2015 ACC/AHA/SCAI focused update on primary percutaneous coronary intervention for patients with stelevation myocardial infarction: an update of the 2011 ACCF/ AHA/SCAI guideline for percutaneous coronary intervention and the 2013 ACCF/AHA guideline for the management of st-elevation myocardial infarction. J Am Coll Cardiol 2016; 67: 1235-1250.

7. Ibanez B, James S, Agewall S, Antunes MJ, Bucciarelli-Ducci C, Bueno H, et al. 2017 ESC Guidelines for the management of acute myocardial infarction in patients presenting with ST-segment elevation: The Task Force for the management of acute myocardial infarction in patients presenting with ST-segment elevation of the European Society of Cardiology (ESC). Eur Heart J 2018; 39: 119-177.

8. Lee PY, Alexander KP, Hammill BG, Pasquali SKD, Peterson ED. Representation of elderly persons and women in published randomized trials of acute coronary syndromes. JAMA 2001; 286: 708-713.

9. Nammas W, de Belder A, Niemelä $M$ et al. Long-term clinical outcome of elderly patients with acute coronary syndrome treated with early percutaneous coronary intervention: Insights from the BASE ACS randomized controlled trial: Bioactive versus everolimus-eluting stents in elderly patients. Eur J Intern Med 2017; 37: 43-48.

10. Orenes-Piñero E, Ruiz-Nodar JM, Esteve-Pastor MA, Quintana-Giner M, Rivera-Caravaca JM, Veliz A, et al. Therapeutic management and one-year outcomes in elderly patients with acute coronary syndrome. Oncotarget 2017; 8: 80182-80191.

11. Bauer T, Möllmann H, Weidinger F, Zeymer U, Seabra-Gomes R, Eberli F, et al. Predictors of hospital mortality in the elderly undergoing percutaneous coronary intervention for acute coronary syndromes and stable angina. Int J Cardiol 2011; 151: 164-169.

12. Tsai TH, Chua S, Hussein H, Leu S, Wu CJ, Hang CL, et al. Outcomes of patients with Killip class III acute myocardial infarction after primary percutaneous coronary intervention. Crit Care Med 2011; 39: 436-442. 
13. Rahman MM, Alam MM, Jahan NA, Shila JS, Arslam MI. Prognostic role of multiple cardiac biomarkers in newly diagnosed acute coronary syndrome patients. Mymensingh Med J 2016; 25: 326-333.

14. Lazzeri $\mathrm{C}$, Valente $\mathrm{S}$, Chiostri $\mathrm{M}$, Attanà $\mathrm{P}$, Mattesini $\mathrm{A}$, Gensini GF. Mechanical ventilation in the early phase of ST elevation myocardial infarction treated with mechanical revascularization. Cardiol J 2013; 20: 612-617.

15. The Global Use of Strategies to Open Occluded Coronary Arteries in Acute Coronary Syndromes (GUSTO IIb) Angioplasty Substudy Investigators A clinical trial comparing primary coronary angioplasty with tissue plasminogen activator for acute myocardial infarction. [published erratum appears in N Engl J Med 1997; 337:2 87]. N Engl J Med 1997; 336: 1621-1628.

16. Rajani R, Lindblom M, Dixon G, Khawaja MZ, Hildick-Smith D, Holmberg S, et al. Evolving trends in percutaneous coronary intervention. Br J Cardiol 2011; 18: 73-76

17. Feldman DN, Gade CL, Slotwiner AJ, Parikh M, Bergman G, Wong SC et al. Comparison of outcomes of percutaneous coronary interventions in patients of three age groups $(<60,60$ to 80 , and $>80$ years). Am J Cardiol 2006; 98: 1334-1339.

18. Rathod K, Knight C. Percutaneous coronary intervention in old age - effective or intrusive? Br J Cardiol 2013; 20: 6-7.

\section{Authorship entitlement}

Excerpts from the Uniform Requirements for Manuscripts Submitted to Biomedical Journals updated November 2003.

Available from www.icmje.org

The international Committee of Medical Journal Editors has recommended the following criteria for authorship; these criteria are still appropriate for those journals that distinguish authors from other contributors.

Authorship credit should be based on 1) substantial contributions to conception and design, or acquisition of data, or analysis and interpretation of data; 2) intellectual content; and 3) final approval of the version to be published. Authors should meet conditions 1,2 , and 3 .

Acquisition of funding, collection of data, or general supervision of the research group, alone, does not justify authorship.

An author should be prepared to explain the order in which authors are listed. 